\title{
Influence of Computerized Accounting Systems on Financial Reporting Quality in Small and Medium Enterprises
}

\author{
Akamanwam Effiong Itang, PhD, FCA. \\ Consulting Accountant, Florina Limited; Seconded to ENI Nigeria (Finance Division), POBox 923, Port \\ Harcourt, Nigeria
}

\begin{abstract}
The prevalence of diverse accounting software or computerized accounting systems and the increased usage of such systems amongst small and medium enterprises (SMEs) globally, as well as the need to present decisionuseful financial reports by SMEs motivated the researcher to undertake this project. The study, therefore, sought to ascertain the relationship between computerized accounting systems and financial reporting quality in small and medium enterprises in Nigeria. The researcher modelled computerized accounting systems (CAS) as the predictor variable with five formative constructs, namely internal controls, automated data-processing, relational database, automated reporting, and enhancing technologies. The dependent (criterion) variable, financial reporting quality (FRQ), was modelled with five dimensions, namely relevance, faithful representation, comparability, verifiability, and understandability. Five hypotheses relating to the extent to which computerized accounting systems influence financial reporting quality in terms of relevance, faithful representation, comparability, verifiability, and understandability, were tested. The study data were collected using a web-based self-completed questionnaire from a sample of 370 firms randomly selected from SMEs in the South-South region of Nigeria, of which 223 completed questionnaires $(60.3 \%)$ were found useful for the study. The collected data were analysed using descriptive statistics and structural equation modelling procedure with the aid of SPSS-Statistics and SPSS-Amos software. The study's findings indicated that CAS usage has a significant positive influence on financial reporting quality in terms of relevance, faithful representation, comparability, verifiability, and understandability. CAS is also indicated to be a good predictor of financial reporting quality. Therefore, all five null hypotheses were rejected. The findings of the study also showed that the most impacted dimension of financial reporting quality by CAS is understandability, while the least impacted is verifiability. Consequently, the researcher concluded that computerized accounting systems significantly enhance the quality of financial reporting information. Hence, there is a need to encourage SMEs to adopt computerized accounting systems to improve their financial reporting quality. Management and those performing accounting functions in SMEs and finance and accounting scholars would find the results of this study extremely useful. The researcher has suggested areas for further studies that would help to validate and, or, extend the study's findings.

Keywords: Accounting information, Accounting information system, Accounting software, Accounting systems, Automated data processing, Automated reporting, Comparability, Computerized accounting system, Enhancing technologies, Faithful representation, Financial information, Financial reporting, Financial reporting information, Financial reporting quality, General systems theory, Internal controls, Relational database, Relevance, Small and medium enterprises, Structural characteristics model, Structural equation modelling, Understandability, Verifiability.
\end{abstract}

DOI: $10.7176 /$ RJFA/12-22-09

Publication date: November 30th 2021

\section{Introduction}

Small and medium enterprises (SMEs) play a vital role in the global economic development. Studies indicate that in the United States (US), SMEs constitute over $99 \%$ of employer firms, while in Nigeria they constitute $95 \%$ of business firm and with significant contribution to the production of good and services, employment, and entrepreneurial capacity building (U.S. Small Business Administration [USSBA], 2018; Aremu \& Adeyemi, 2011). However, SMEs witness a relatively high failure rate, resulting from several factors including poor business experience, poor business management skills, lack of adoption of technological tools, lack of access to finance, and poor financial reporting quality (Alsaaty, 2012; Okoli, 2011). These failure factors are interrelated; for example, inadequate financial record-keeping could be a result of lack of technological tools adoption, which can in turn result in low quality of financial reports, and consequently, lack of access to finance (Afolabi, 2013). Therefore, it is expedient to consider the mechanisms that would enhance SMEs' success and performance in improving their accounting records-keeping practices and financial information quality. One of the primary tools for achieving this goal is the adoption and implementation of good accounting information systems (AIS). As defined by Hurt (2014, pp.4), an AIS is "a set of interrelated activities, documents, and technologies designed to collect data, process it, and report information to a diverse group of internal and external decision-makers in organizations." Considering this definition, an accounting system without technological enhancement would certainly be incomplete, inadequate, and inefficient in the light of today's business environment. Therefore, as a 
working definition, a computerized accounting system is an integration of computer-based schemes, applications, and infrastructure employed by an entity in collecting, recording, organizing, storing, and analyzing financial transactions and to interpret and communicate financial information to stakeholder for informed decision making. The prevalence of diverse computerized accounting systems or accounting software and the increased usage of such systems amongst small and medium enterprises (SMEs) globally, as well as the need to present decisionuseful financial reports by SMEs form the motivation for this study.

Though SMEs are mostly private firms and, therefore, are not exposed to stringent regulations and legal requirements regarding financial reporting as is the case with large and public firms, they also need good quality financial reports to enhance sound business decisions as well as place them in vantage positions in their quest for financial assistance, loans, and credits, especially as banks and other providers of funds base their primary assessment of firms for lending purposes on the information presented in the financial reports (Afolabi, 2013; IASB, 2015). As noted by Sacer and Oluic (2013), using computer-based systems in the accounting process would aid the production of useful accounting information, which implies that computerized accounting systems could influence the financial reporting quality of business organizations. Several studies have been conducted on the relationship between accounting information systems and financial information quality around Europe, United States, and Asia (for example: Adbullah, 2013; Al-Dalabih, 2018; Fardinal, 2013; Masanja, 2019; Wisna, 2013). However, no study has been identified by the researcher to examine the influence of computerized accounting systems on financial reporting quality among Nigerian SMEs. A few identified empirical studies on computerized accounting and SMEs in Nigeria focus on the issues of adoption, implementation, and internal controls (e.g., Ige, 2015; Itang, 2018). There is, therefore, scarcity of research work on the influence of computerized accounting systems on the quality of financial reporting information among SMEs, and this has created a gap in the literature in this crucial and fast developing area of accounting and finance. To fill this gap, this study sought to examine the relationship between computerized accounting systems and financial reporting quality in small and medium enterprises in Nigeria.

Therefore, the main objective of the study was to determine the extent to which computerized accounting systems influence the quality of financial reporting information among small and medium enterprises, in terms of relevance, faithful representation, comparability, verifiability, and understandability. To achieve this objective, the research question was posed, thus: to what extent do computerized accounting systems influence the quality of financial reporting information among small and medium enterprises, in terms of relevance, faithful representation, comparability, verifiability, and understandability. In view of this research question, the following five hypotheses were tested in the study.

Ho1. Computerized accounting systems do not significantly influence relevance of financial reporting information in SMEs.

Ho2. Computerized accounting systems do not significantly influence faithful representation of financial reporting information in SMEs.

Ho3. Computerized accounting systems do not significantly influence comparability of financial reporting information in SMEs.

Ho4. Computerized accounting systems do not significantly influence verifiability of financial reporting information in SMEs.

Ho5. Computerized accounting systems do not significantly influence understandability of financial reporting information in SMEs.

In the context of this study, computerized accounting systems are conceptualized as the application of computer-based technologies by an entity in the process of collecting, recording, organizing, processing, and analyzing accounting data, and interpreting and communicating accounting information to its stakeholders for informed decision making. Computerized accounting systems (CAS) have been operationalized based on Itang's (2020a) structural characteristics model, which decomposed CAS into five components, namely internal controls, automated data processing, relational database, automated reporting, and enhancing technologies. Financial reporting quality (FRQ) is conceptualized as the extent to which financial reporting information meets its fair presentation and decision-usefulness objectives. FRQ is operationalized using the qualitative characteristics of decision-useful financial information presented in the International Accounting Standards Board (IASB) conceptual framework for financial reporting (excluding timeliness), namely relevance, faithful representation, comparability, verifiability, and understandability (IASB, 2010, 2018). Timeliness was excluded from the dimensions of FRQ because it is indicated to be measured with the length of time-lag for auditors to sign the audit report after the book-year end (see Mbobo \& Ekpo, 2016; van Beest et al., 2009), a parameter that is outside the functionalities of the computerized accounting system.

The study is significant as it provides empirical evidence on the relationship between computerized accounting systems and the quality of financial reporting information among Nigerian SMEs using the structural characteristics model instead of the usually adopted systems' qualitative characteristics. 


\section{Literature Review}

The review of literature for this study focused on the theoretical framework of the study, overview of the concepts of computerized accounting systems and financial reporting quality, computerized accounting systems and financial reporting quality in small and medium enterprises, and influence of computerized accounting systems on financial reporting quality.

\subsection{Theoretical Framework}

Theoretical framework provides an underpinning, based on existing theory or theories, for the research process. This study examines the relationship between computerized accounting systems and the financial reporting quality of SMEs in Nigeria and is founded on the general systems theory, focuses on the holistic approach to understanding an entity's functioning through the interactions and relations among its various parts (von Bertalanffy, 1950, 1968, 1972; Mele et al., 2010). Von Bertalanffy $(1950 ; 1968 ; 1972)$ noted that the knowledge of the parts of an entity and how they relate to each other is required to clearly understand how the entity is organized as whole and how it works. Mele et al. (2010), in their review of the application of systems theory in management practice, noted that the application of systems theory would contribute to effective business research as it considers study phenomenon as a holistic piece while analyzing individual components of the entity. The general systems theory is useful in framing this study because computerized accounting systems are characterized by functional components or subsystems that are designed to work harmoniously together towards achieving the overall objective of the system. More so, the theory helps in providing understanding about the relationships among system elements towards achieving the overall goals of the system. Based on the general systems theory, the study examines how computerized accounting systems, through the interplay of their various components, effectively fulfill their financial reporting objective.

\subsection{Overview of Computerized Accounting Systems (CAS)}

An accounting systems is defined as "a set of interrelated activities, documents, and technologies designed to collect data, process it, and report information to a diverse group of internal and external decision-makers in organizations" (Hurt, 2013, p. 4). Computerized accounting systems are methods and schemes employed to record, organize, summarize, analyze business transactions, and interpret or communicate financial information to stakeholders using computers and related technologies (Marivic, 2009). As a working definition, a computerized accounting system is an integration of computer-based schemes, applications, and infrastructure employed by an entity in collecting, recording, organizing, storing, and analyzing financial transactions and to interpret and communicate financial information to stakeholder for informed decision making. Since technological innovation and advancement are generally aimed at enhancing human performance, computerized accounting systems are, therefore, designed and equipped with automated functionalities to enable organizations to overcome the challenges and drawbacks of manual accounting systems. As indicated by Ismail and King (2007), computerized accounting systems enhance information flow, employee performance, and financial information accuracy in organizations. This position is supported by Sajady et al. (2008), who indicated that the application of computerized accounting information systems helps to improve the decision-making of managers and the quality of financial reporting.

Computerized accounting systems are characterized by process integration, accessibility, reliability, and flexibility (Anggraeni, 2016). Process integration implies that different processes performed independently in a manual system are carried out in an integrated automated manner, such that activities including data capturing, transactions posting, and ledger accounts balancing are performed almost simultaneously without human intervention. Accessibility implies that system users can easily access and retrieve data and information stored in the system. In contrast, flexibility and reliability suggest that the system makes the accounting function and reporting process very dynamic and its output more reliable. Accounting information systems have also been assessed in terms of their qualitative characteristics, such as speed, accuracy, timeliness, information scope, and ease of use (for example: Choe, 1998; Doll \& Torkzadeh, 1988a, 1988b; Meiryani et al., 2019). These identified characteristics and advantages of computerized accounting systems, such as speed, integration, accuracy, flexibility, reliability, and automation, are enabled by the consolidated functions and synergy of the various components of the system (Agung, 2015; Anggraeni, 2016; Ghasemi et al., 2011; Itang, 2021).

In general terms, an accounting information system consists of five major components or elements, namely inputs, processes, outputs, storage, and internal controls (Hurt, 2013; Paganini, 2019; Surendar \& Rathnakar, 2019). However, Itang (2020a) identified five structural components of computerized accounting systems, namely internal controls, automated data-processing, relational database, automated processing, and enhancing technologies. Itang (2021) provided empirical evidence that each of these components contributes positively and significantly to the overall performance of computerized accounting systems, and hence posited that all five components are necessary in the design and modelling, as well as the choice and adoption, of computerized accounting systems for SMEs. In this study, these five components would be considered in conceptualizing and 
operationalizing computerized accounting systems.

\subsubsection{Internal Controls}

Internal control is “a process effected by an entity's board of directors, management, and other personnel, designed to provide reasonable assurance regarding the achievement of objectives relating to operations, reporting, and compliance" (Committee of Sponsoring Organizations of the Treadway Commission [COSO], 2013, pp. 3). A study conducted by Steckel (2011) on the utilization of internal controls capabilities in QuickBooks accounting software by SMEs, indicated that the accounting software has built-in internal controls features such as user access and roles controls, data input controls, audit trail, among others, which enabled the system to maintain the integrity of data, process standardization, accuracy, and reliability of outputs and reports. Fardinal (2013), and Qatanani and Hezabr (2015) also indicated that computerized accounting systems are enhanced with built-in internal control functionalities that enable the system to establish and execute various internal accounting and administrative controls at various stages of the accounting process, including preparation of financial statements. More so, Itang (2021) indicated that internal control component play a significant role on the overall performance of computerized accounting systems; while Itang (2020b) indicated that the built-in internal controls in CAS have been implemented to a large extent by Nigerian SMEs.

\subsubsection{Automated Data-processing}

The accounting cycle involves several steps and stages, including opening entries, identification and analysis of transactions, journalizing, ledger accounts posting, ledger accounts balancing, trial balance extraction, adjustments posting, and preparation of financial statements (Hurt, 2013); Kapasi, 2017). In computerized accounting systems, these steps are carried out automatically, seamlessly, and almost simultaneously by the automated data-processing subsystem with the click of a button (Anggraeni, 2016; Ghasemi et al., 2011; Hurt, 2013; Itang, 2020a, 2021; Sacer \& Oluic, 2013)

\subsubsection{Relational Database}

Computerized accounting systems are characterized by relational database management subsystems, which helps in the storage, maintenance, and utilization of large collection of data as well as the preservation of data independence, integrity, scalability, and concurrent access (Agung, 2015; Itang, 2020a; Ramakrishnan \& Gehrke, 2003). The relational database component of CAS enables the effective manipulation and retrieval of data and information from the system by creating distinct relationships between individual ledger accounts and between accounts and other financial records and files (Agung, 2015; Islam \& Abedin, 2013; Itang, 2021; Rani \& Kidane, 2012; Satalkar, 2018).

\subsubsection{Automated Reporting}

The automated reporting component is the subsystem that handles the reporting process in the accounting system. It enables the system to automatically generate various form of reports and financial statements, based on predefined parameters (Hurt, 2013; Itang, 2020a, 2021).

2.2.5 Enhancing Technologies

Itang (2020a, p. 42) defined CAS enhancing technologies as "secondary technological tools on which the accounting system depends to function effectively". In other word, enhancing technologies are the devices and applications that support the computerized accounting system to perform its designated functions effectively and efficiently. They include networking infrastructure, web and cloud technologies, printing and imaging devices, email applications, etc. (Itang, 2020a, 2021).

\subsection{Overview of Financial Reporting Quality}

The final goal of every accounting system is to provide financial information to both internal and external stakeholders. However, such information would be useless or misleading if they lack the desired quality. The quality of financial reporting information, therefore, anchors on the extent to which the information in the financial statements and explanatory notes is fairly presented. The concept of financial reporting quality as gained greater attention in recent times following the emergent of accounting scandals such as the cases of Enron, Worlcom, Parmalat, Sunbean, and Macroni, which gave rise to the global financial crises and loss of investors' confidence (Agrawal \& Chadha, 2005).

The quality of financial reporting information is defined using several models, such as the accrual model, which is based on the level of discretionary accruals employed by management in the measurement of earnings; the value relevance model, which measures the relevance and reliability of financial information based on the relationship between stock returns and earnings figures; the financial report elements model, which focuses on the quality of specific items in the financial reports; and the qualitative characteristics model, which considers the qualitative characteristics of useful financial information as the measure of financial reporting quality(Al-Dmour et al., 2017; Chen, 2012; Mbobo \& Ekpo, 2016; Nichols \& Wahlem, 2004; Seyed, 2014; van Beest et al., 2009). Among these models, the qualitative characteristics model has been indicated to be the most recent approach to measuring financial reporting quality (Mbobo \& Ekpo, 2016), and the most employed framework in the qualitative characteristic model has been the International Accounting Standards Board (IASB) conceptual framework, which 
provides six qualitative characteristics of useful financial information, namely relevance, faithful representation, comparability, verifiability, timeliness, and understandability (IASB, 2010, 2018).

\subsubsection{Relevance}

Financial information is said to be relevant if it can make a difference in the users' decisions. (IASB, 2010, 2018).

The relevance of financial information is affected by its materiality. A piece of information is material if its omission or misstatement could influence users' economic decisions based on the financial report (Al-Dmour et al., 2017; IASB, 2010, 2018). Relevant financial information must have either predictive and confirmatory value or both (Ernst \& Young, 2010; Greuning et al., 2011; IASB, 2010, 2018). As indicated by van Beest et al. (2009), financial information has predictive value if it presents forward-looking statements on future expectations, discloses information about business opportunities and risks, and is based on fair value accounting. It is also argued that fair value accounting presents better predictive value and relevant information than historical cost as it portrays the current value of items instead of their purchase price (McDaniel et al., 2002; Maines \& Wahlen, 2006). Mbobo and Ekpo (2016) also indicated that the relevance characteristic had been perceived to have a high potential to enhance financial reporting quality.

\subsubsection{Faithful Representation}

Faith representation is the second fundamental qualitative characteristics of useful financial information and is indicative of financial information that is complete, neutral, and free from material error (Al-Dmour et al., 2017; IASB, 2010, 2018). Ernst \& Young (2010) noted that faithful representation replaces the term "reliability" to ensure clarity and common understanding in relation to its meaning. Faithful representation of financial information would be guaranteed when financial statements are based on estimates and assumptions that match the underlying economic constructs and standards, as well as highlight in a neutral manner both positive and negative economic events (IASB, 2010, 2018; Maines \& Wahlen, 2006; van Beest et al., 2009).

\subsubsection{Comparability}

This enhancing qualitative characteristic of financial information enables users to compare items in the financial statements between different reporting periods and across different reporting entities (Al-Dmour et al., 2017; IASB, 2010, 2018; EY, 2010). Comparability of financial information would be assured when similar situations are presented in the same manner, while differing situations should also be presented differently (Mbobo \& Ekpo, 2016; van Beest et al., 2009). Therefore, comparability of financial information requires consistency in accounting policies and procedures, accounting estimates and adjustments, and information on any changes therein (EY, 2010). 2.3.4 Verifiability

Verifiability is a new concept and enhancing qualitative characteristics of useful financial information introduced by IASB in the conceptual framework issued in 2010. Verifiability ensures that financial information enables knowledgeable and independent observers to reach a consensus on the faithful representation of an event depicted in the financial report (EY, 2010; IASB, 2010, 2018). Therefore, this characteristic of financial information enhances the authentication of economic events and figures presented in the financial reports.

\subsubsection{Timeliness}

The IASB conceptual framework presents timeliness under the enhancing qualitative characteristics of useful financial information and defines it as making information available to users and decision-makers before it loses its decision-influencing capacity (Al-Dmour et al., 2017; IASB, 2010, 2018). This fact implies that the financial report's timing can either ensure or mar the reliability of information presented (EY, 2010). The timeliness of financial reporting information is usually measured using the number of days it takes the auditor to sign the financial reports after the accounting book-year end (Mbobo \& Ekpo, 2016; van Beest et al., 2009).

\subsubsection{Understandability}

Understandability is the degree to which users easily understand the information presented in the financial statements. Understandability of financial information would be assured through clear and concise classification, characterization, and presentation (Al-Dmour et al., 2017; EY, 2010; IASB, 2010, 2018). Though listed as the last in the framework, this information characteristic is vital in enhancing the relevance and faithful representation of financial information and its decision usefulness, as the information presented cannot be said to be relevant or faithfully represented if they are not clear and understandable. The understandability of financial information can be measured using (i) organization and presentation of financial reports, (ii) information disclosed in the Notes to the Accounts, (iii) use of tables and graphs, (iv) avoidance of technical jargons, and (v) inclusion of a glossary of unfamiliar word and terminologies (Mbobo \& Ekpo, 2016; van Beest et al., 2009).

\subsection{Computerized Accounting and Financial Reporting in Small and Medium Enterprises}

Small and medium enterprises (SMEs) have been defined differently by different countries and economic jurisdictions. This situation is prompted by the dynamic nature and environmental diversity of SMEs, and peculiar economic circumstances prevalent in in various countries. The divergence in the definition of SMEs by various countries, economic jurisdictions, and various interest groups is in line with the provisions of International Financial Reporting standards for SMEs (IFRS for SMEs), which allows each country or jurisdiction to determine 
the criteria for qualifying firms as SMEs based on their circumstance (IASB, 2015). In Nigeria, small and medium enterprises are defined by the National Policy on Micro, Small and Medium Enterprises as businesses whose total value of assets ranges between N5 million to N500 million (excluding land and building) and whose number of employees ranges between 10 to 199 employees (SMEDAN, 2013).

Financial reporting practices in SMEs have been indicated to be motivated by several factors including profitability, tax returns, age and size of the firm, nature of the firm's industry, knowledge and skills of owners, and regulatory pressure (Ismail \& King, 2007; Lalin \& Sabir, 2010; Tanwongsval \& Pinvanichkul, 2008). These motivating factors, notwithstanding, SMEs face some challenges in their accounting and financial reporting processes. Such challenges range from ownership structure, the limited number of employees to the nature of accounting systems in use (Onugu, 2005; Mujat et al., 2013). As indicated by Onugu (2005), most SMEs lack proper financial records due to their owners' and managers' inadequate knowledge of financial management and deliberate attempts to conceal their performance from competitors. An exploratory study conducted by Obamuyi (2007) on SMEs and loan delinquency in the Ondo State of Nigeria indicated that SMEs failed to meet the criteria for bank loan assessment due to their inadequate accounting and financial reporting practices. This situation has prompted lenders to make extra demands, such as the mandatory provision of collateral, in their process of assessing loan applications. To overcome this challenge, Richard et al. (1991) recommended that SMEs embrace and implement computerized accounting systems to enhance their accounting and financial reporting practices.

Itang (2020b), in a study conducted on the implementation of computerized accounting systens internal controls by SMEs in Nigeria, employed the survey methodology using self-completed questionnaires administered to a sample of 370 firms. The result of the study indicated that Nigerian SMEs are increasingly adopting computerized accounting systems. The study also showed that Sage 50 (formerly Peachtree) is the most used accounting software, followed by QuickBooks and Tally ERP. The study also indicated other accounting software employed by SMEs to include Busy Accounting, Sage Pastel, MetroPCS, First Class, Invex, MS Dynamics, MS Excel, MS Navision, and Software. A study on the usage of computerized accounting systems in Kumasi Metropolis of Ghana carried out by Amanamah et al. (2016) also employed the survey methodology using questionnaires administered to a sample of 367 firms from a total population of 4,500 SMEs. The study indicated that $74 \%$ of the firms used computers in their business operations, with $62 \%$ of the firms engaging computerized accounting systems in their accounting function. The study also indicated the most used accounting software by SMEs in Kumasi, Ghana to be Excel (40\%), Sage Accounting (21\%), Tally (17\%), Pastel (15\%), and QuickBooks (6\%). Frimpong et al. (2018) conducted a similar study on computerized accounting systems' adoption in Ghana. They employed the stratified random sampling method and survey questionnaires administered to a sample of 43 subjects, and the results indicated that Ghanaian firms adopt computerized accounting systems in their operations. They also showed that MS-Excel, Sage, Tally, and SAP are the most used accounting systems with a usage rate of $93 \%, 39 \%, 37 \%$, and $20 \%$, respectively.

Evidence from advanced countries also indicates that most SMEs use computerized accounting systems, which has helped improve their accounting process and the firms' quality of accounting information. For example, Gorton (1999), in a comparative study of SMEs in the UK, indicated that over $60 \%$ of the 366 firms studied used computerized accounting systems to enhance their financial planning. Another empirical study by Grande et al. (2011) on the impact of accounting information systems on SMEs' performance measures in Spain reveals that Spanish SMEs use computerized accounting systems to enhance their economic returns, profitability, and productivity through effective banking and fiscal management.

However, the inability of SMEs to provide quality financial information has been indicated by Boateng and Abdulrahman (2013), a situation that is also indicated to impede the assessment of their creditworthiness by financial institutions. The above issue becomes critical as financial institutions do not rely only on firms' feasibility reports in assessing SMEs but much more on the accounting information made available to them (Ohachosim et al., 2012). This fact buttresses the significance of financial reporting information and the need for acceptable accounting practices in SMEs. In a bid to facilitate the improvement in the accounting and financial reporting practices of Nigerian SMEs, the Federal Government of Nigeria, as part of its International Financial Reporting Standards (IFRS) adoption process, required all SMEs to prepare their financial reports in accordance with the IFRS (particularly, IFRS for SMEs), with effect from January 1, 2014 (Nigerian Accounting Standards Board [NASB], 2010). Given this development and considering the increased adoption of computerized accounting systems by SMEs in the advanced countries, Nigeria, and other African countries, as indicated in the above review, the present study sought to investigate the extent to which computerized accounting systems relate to the quality of financial reporting information in Nigerian SMEs.

\subsection{Influence of Computerized Accounting Systems on Financial Reporting Quality}

Research around computerized accounting systems and their relationship with financial reporting quality is relatively scarce, particularly within the Nigerian and small and medium enterprises context. Amidu et al. (2011) investigated e-Accounting (computerized accounting) practices amongst Ghanaian SMEs, which indicated that 
SMEs in Ghana implement various kinds of accounting software with various functionalities. However, they did not consider the effect of computerized accounting systems on financial reporting quality.

Empirical studies on the impact of computerized accounting (or accounting information) systems on the effectiveness of the accounting function, generally, include Kapasi (2017), Rani and Kidane (2012), and Sajady et al. (2008). Kapasi (2017) investigated the effectiveness and impact of computerized accounting systems (CAS) on accounting functions generally among firms in Bengal, while Sajady (2008) and Rani and Kidane (2012) conducted similar studies in Tehran - Iran, and Ethiopia, respectively. The results of the three studies indicated that CAS has a significant impact on the effective performance of the accounting function and processing of financial transactions in terms of speed, accuracy, automated validation and processing of data, and reporting. However, the studies only considered the effectiveness of computerized accounting systems and how they impact the accounting function's performance generally without emphasizing any aspect of the accounting process, such as financial reporting.

There are other studies that are related to the present study in terms of the subject area, which investigated the relationship between computerized accounting information systems and financial reporting quality. However, most of such studies were conducted outside the Nigerian environment and SMEs context. Soudani (2013) investigated the impact of e-accounting systems on financial performance through internal controls in listed firms in the United Arab Emirates, using a population of financial managers, accountants, and auditors, and found that e-accounting systems significantly impact financial performance of firms in terms of profitability, efficiency, liquidity, and financial information reliability. Attayah and Sweiti (2014) studied the impact of enterprise resource planning (ERP) systems adoption on financial information relevance among Saudi Arabian firms. They found that firms that adopted ERP systems had improved information relevance in terms of predictive value, timeliness, and feedback value than those that did not adopt ERP systems. However, similar studies by conducted by Aryani and Krismiaji (2013) and conducted in Indonesia Pervin et al. (2019) in Indonesia and Bangladesh, respectively, indicated a negative relationship between ERP adoption and financial reporting information in terms of relevance, faithful representation, and verifiability. In other words, their results showed that ERP implementation decreases relevance, faithful representation, and verifiability of financial information.

Kanakri (2016) examined the effect of accounting information systems usage on accounting information quality among Jordanian firms, using quantitative survey research and a sample of 180 accounting information users such as accountants, investors, auditors, financial analysts, and academics. The results of the study indicated that accounting information systems enhance accounting information quality by about $72 \%$. Susanto (2017), using descriptive exploratory research with a sample of 37 universities, investigated the impact of accounting information systems quality on accounting information quality among Indonesian higher education institutions. The overall results of the study revealed a standardized beta of 0.369 for the relationship between accounting information systems (AIS) and accounting information quality, which implied that AIS has a 36.9\% influence on the quality of accounting information.

Mbila (2020) also examined the impact of AIS usage on the quality of financial reports in the Ghanaian banking sector, using the survey methodology. The results of the study indicated that a unit increase in the effective usage of computerized accounting information systems would effectively enhance financial reporting quality by $50 \%$, which showed a positive and significant relationship. Mbila's (2020) findings supported the results of a similar study conducted by Sekyere et al. (2017) on the same Ghanaian banking sector, using the same approach, though they incorporated staff competence as co-predictor variable with accounting information systems. Sekyere et al. (2017) indicated that financial reporting accuracy is a function of computerized accounting systems and staff competence.

Abdallah (2013) and Kanakriyah (2016) investigated the impact of accounting information systems on the quality of financial statements or accounting information amongst firms in Jordan. Zare (2012) also investigated accounting information systems' effect on the qualitative measures of accounting information among firms in Tehran, Iran, while Shiraj's (2015) study on the impact of computerized accounting systems on financial reporting amongst SMEs in Sri Lanka. These three studies also indicated a positive relationship between computerized accounting systems and the quality financial reporting information. However, they were conducted outside the Nigerian environment and, except Shiraj (2015), they all focused on large firms.

The present study aimed to fill the gap identified in the literature by providing empirical evidence on the relationship between computerized accounting systems and the quality of financial reporting information amongst SMEs in Nigeria. The study deviates from previous studies in that it focuses on small and medium enterprises in Nigeria. It also measures all the quality dimensions of financial information (excepting timeliness), using the qualitative characteristics model instead of the accruals model; whereas previous studies, individually, considered at most three of the dimensions of financial information quality, with some of them employing the accruals model in the measurement of financial information quality. 


\subsection{Conceptual Model of the Study}

Based on the literature review, the model of the study was conceptualized as shown in Figure 1. Computerized accounting systems (CAS) is decomposed into five formative constructs adopted from Itang (2020a), namely internal controls, automated data-processing, relational database, automated reporting, and enhancing technologies. The model shows the hypothesized relationships between CAS, represented by the synergy of its formative constructs, and each of the dimensions of financial reporting quality, namely relevance, faithful representation, comparability, verifiability, and understandability. This study aimed to ascertain the existence and significance of these relationships.

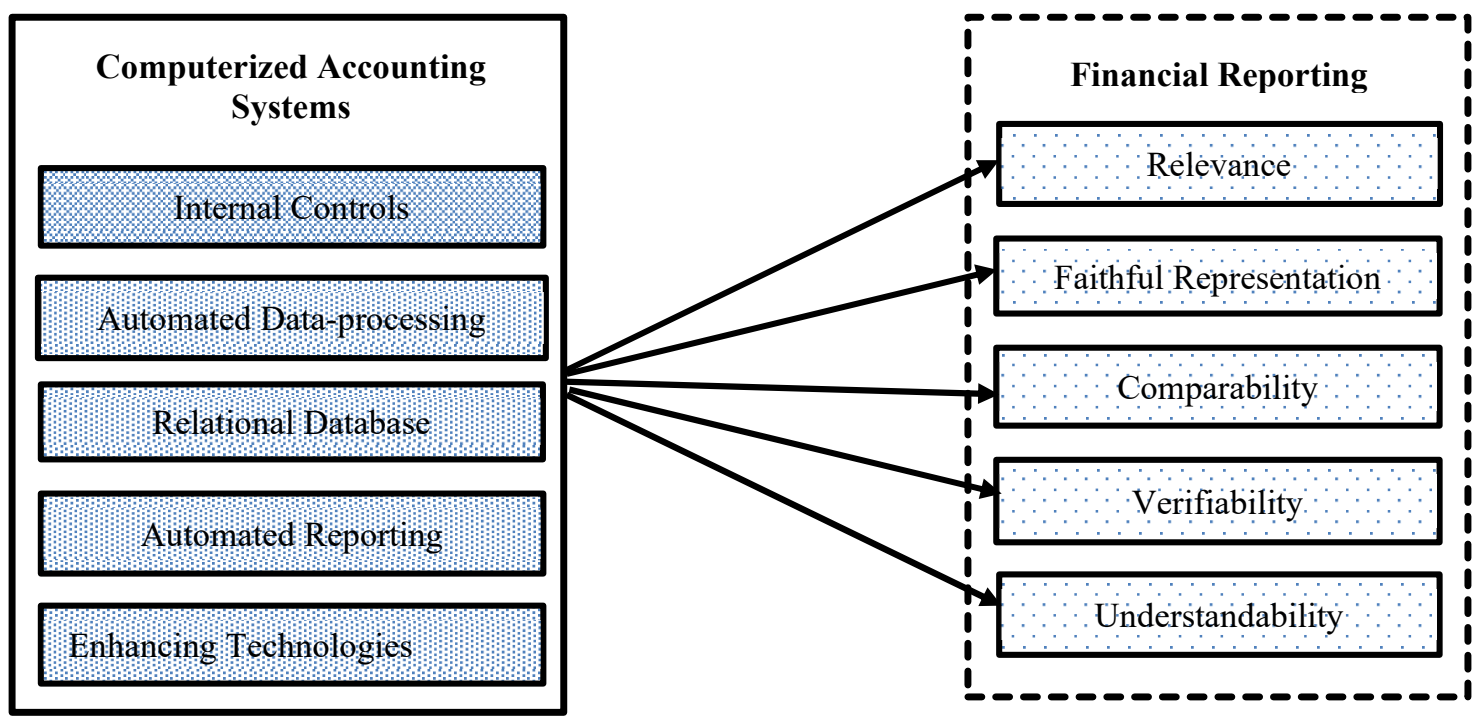

Figure 1. Conceptual Model of the Study

Note: Conceptualized by the researcher based on literature review

\section{Methods}

\subsection{Study Design}

This is a quasi-experimental, cross-sectional survey study. Particularly, the study employs an analytical survey, which is useful for determining the relationship between sets of variables (Collis \& Hussey, 2014). The researcher deemed this approach appropriate as this study seeks to determine the relationships between computerized accounting systems and the measures of financial reporting quality. Computerized accounting systems, which represents the independent (predictor) variable, was modelled using the five structural characteristics (or functional components) of computerized accounting systems indicated by Itang (2020a), namely internal controls, automated data processing, relational database, automated reporting, and enhancing technologies subsystems; while financial reporting quality, which represents the dependent (criterion) variable, was modelled using five of the qualitative characteristics of decision-useful financial information indicated in the IASB's Conceptual Framework for Financial Reporting (IASB, 2010, 2018), namely relevance, faithful representation, comparability, verifiability, and understandability

\subsection{Study Population and Sample}

The population of the study was limited to SMEs in the South-South region of Nigeria, which has a total of 9,276 firms as indicated by SMEDAN (2013). The stratified random sampling technique was employed in selecting the sample for the study based on the States of operation of the firms. The stratified random sampling technique involves splitting the study population into distinct strata or subgroups and then carrying out a random selection of a proportional number of members from each unit or stratum. This process helps to ensure adequate representation of the study population and avoid the under-representation (or over-representation) of some population members typically associated with the simple random sampling technique (Collis \& Hussey, 2014; Kpolovie, 2016; Salhin et al., 2016). The sample size of 370 firms was considered adequate based on Krejcie and Morgan's sample size determination table (Krejcie \& Morgan, 1970, p. 608).

\subsection{Data Collection and Analysis}

The research data was collected using self-completed survey questionnaires administered to one accounting and finance officer from each of the 370 sampled firms. A five-point Likert-type 25 -item measurement scale, with ratings ranging from (1) strongly disagree to (5) strongly agree, adopted from Itang (2020a) was used to collect 
data on computerized accounting systems; while a 21-item Likert-type rating scale, which ranged from (1) very little extent to (5) very large extent, used in collecting data on financial reporting quality was adopted with modification from van Beest et al. (2009). Two hundred and twenty three (223) useful responses where received (about $60.3 \%$ response rate) and used in the analysis. Descriptive data analysis was performed using the SPSSStatistics software, while the inferential analysis was performed using structural equation modelling with the aid of SPSS-Amos software. The choice of SEM for the inferential analysis was informed by the fact that it has been indicated to be a useful tool when dealing with multiple independent and dependent variables and is helpful in answering several research questions as well as testing several hypotheses in a single systematic and comprehensive analysis by modeling the relationships between the multiple variables at the same time (Bagozzi \& Yi, 2012; Rae et al., 2016).)

\subsection{Operationalization of Study Variables}

Computerized accounting systems (CAS), the independent (predictor) variable, was operationalized with five constructs adopted from Itang (2020a), namely internal controls, automated data-processing, relational database, automated reporting, and enhancing technologies, denoted by IC, AD, RD, AR, and ET, respectively. Each of these constructs was measured with five indicators (or observed variables), which gave a total of 25 indicators for the CAS high order predictor variable. The dependent (criterion) variable, financial reporting quality (FRQ), was operationalized using five of the IASB (2018) qualitative characteristics of decision-useful financial information, namely relevance, faithful representation, comparability, verifiability, and understandability, denoted by RR, RF, $\mathrm{RC}, \mathrm{RV}$, and RU, respectively. The dimensions of financial reporting quality (FRQ) were measured with four indicators for RR, five indicators for $\mathrm{RF}$, six indicators for $\mathrm{RC}$, four indicators for $\mathrm{RV}$, and five indicators for $\mathrm{RU}$, which gave a total of 24 indicators (or observed variables) for the FRQ high order criterion variable. Table 1 and Table 2 highlight the operational measures for the predictor variable (CAS) and criterion variable (FRQ), respectively.

Table 1. Operational Measures of the Study Predictor Variable (CAS)

\begin{tabular}{llll}
\hline Variable Type & $\begin{array}{l}\text { Higher-order } \\
\text { Construct }\end{array}$ & First-order Dimension & Indicator \\
\hline Predictor & $\begin{array}{l}\text { Computerized } \\
\text { accounting } \\
\text { systems (CAS) }\end{array}$ & Internal controls (IC) & IC1 - Access control \\
& & IC2 - Segregation of duties \\
& & IC3 - Accuracy checks \\
& Automated data-processing (AD) & IC4 - Security controls \\
& & IC5 - Audit trail \\
& & AD1 - Seamless processing \\
& & AD2 - Data validation \\
& Relational database (RD) & AD3 - Transaction posting \\
& & AD4 - Accounts reconciliation \\
& & AD5 - Accounts reconciliation \\
& & RD1 - Large storage capacity \\
& & RD2 - Data maintenance \\
& & RD3 - Data independence \\
& & RD4 - Backup and recovery \\
& & RD5 - Concurrent access \\
& & AR1 - Seamless reporting \\
& & AR2 - Trial balance/GL report \\
& & AR3 - Financial statements \\
& & AR4 - Multiple reporting options \\
& & AR5 - Comparative reporting \\
& & ET1 - Network configuration \\
& & ET2 - Cloud computing \\
& & ET3 - POS interface \\
& & ET4 - Document uploads \\
& & ET5 - Email/SMS interface \\
\hline
\end{tabular}

Note: Operationalized by the Researcher based on Itang‘s (2020a) Structural Characteristics Model 
Table 2. Operational Measures of the Study Criterion Variable (FRQ)

\begin{tabular}{llll}
\hline Variable Type & $\begin{array}{l}\text { Higher-order } \\
\text { Construct }\end{array}$ & First-order Dimension & Indicator \\
\hline Criterion & Financial reporting & Relevance (RR) & RR1 - Forward-looking information \\
& quality (FRQ) & & RR2 - Opportunities/risks \\
& & RR3 - Fair-value reporting \\
& Faithful representation (RF) & RR4 - Impact of events/transactions \\
& & RF1 - Standardized estimates \\
& & RF2 - Accounting policies disclosure \\
& & RF3 - Neutrality \\
& & RF4 - Unqualified audit reports \\
& & RF5 - Corporate governance \\
& & RC1 - Policy changes information \\
& & RC2 - Implementation of changes \\
& & RC3 - Prior-year adjustments \\
& & RC4 - Prior-year comparatives \\
& & RC5 - Industry comparatives \\
& Verifiability (RV) & RC6 - Ratios/Index numbers \\
& & RV1 - Agreeable peer verification \\
& & RV2 - Figures/events authentication \\
& & RV3 - Assumptions disclosure \\
& & RV4 - Transactions traceability
\end{tabular}

Note: Operationalized by the Researcher based on the Review of Literature

\subsection{Reliability Test}

The measurement scales used for the evaluation of CAS were adopted from the CAS measurement tool developed by Itang (2020a), while the measurement scales for the assessment of FRQ was adopted from van Beest et al. (2009). These two tools have been employed in previous studies and indicated to have strong validity and high reliability (see Al-Dweikat \& Nour, 2018; Ironkwe \& Nwaiwu, 2018; Itang, 2020b; Mbobo \& Ekpo, 2016; van Beest et al., 2009). Nevertheless, to boost the researcher's confidence in the research instrument, the composite reliability (CR) test, which helped to ascertain the level of association existing between the constructs and their respective indicators, was performed. The CR values obtained ranged between 0.882 and 0.912 for computerized accounting systems constructs and 0.887 and 0.964 for the dimensions of financial reporting quality, which indicated strong and satisfactory reliability.

\section{Study Results}

\subsection{Demographic Data Analysis}

The demographic data gathered in the study were analyzed in terms of the firms' legal forms, job titles of the respondents, and the length of years the firms employed their current computerized accounting systems.

Table 3. Distribution of Firms by Legal Form

\begin{tabular}{lrrr}
\hline Legal Form & Frequencies & Percent & Cum. \% \\
\hline Family-Owned & 2 & 0.9 & 0.9 \\
Partnership & 24 & 10.8 & 11.7 \\
Private Limited Company & 167 & 74.9 & 86.5 \\
Sole-Proprietorship & 30 & 13.5 & 100.0 \\
Total & 223 & 100.0 & \\
\hline \multicolumn{2}{c}{ Note: Extracted by the researcher from research data analysis output }
\end{tabular}

Table 3 presents the distribution of the respondents' firms by their legal form, and it indicates that only two firms $(0.9 \%)$ were family-owned, 24 firms $(10.8 \%)$ were partnerships, 30 firms $(13.5 \%)$ were sole proprietorships, while 167 firms $(74.9 \%)$ were private limited liability companies. These statistics imply that most SMEs in Nigeria are private limited liability companies, while family-owned firms are relatively few. 
Table 4. Distribution of Respondents by Job Title

\begin{tabular}{|c|c|c|c|}
\hline Job Title & Frequency & Percent & Cum. \% \\
\hline Accountant/Accounts Officer & 94 & 42.15 & 42.15 \\
\hline Chief Accountant & 50 & 22.42 & 64.57 \\
\hline Auditor & 9 & 4.04 & 68.61 \\
\hline Finance/Accounts Manager & 45 & 20.18 & 88.79 \\
\hline Chief Finance Officer/Financial Controller & 25 & 11.21 & 100.00 \\
\hline Total & 223 & 100.00 & \\
\hline
\end{tabular}

Note: Extracted by the researcher from research data analysis output

Table 4 presents the distribution of the respondents' official job title. As shown in Table 22, 94 (42.15\%) of the respondents had Accountants or Accounts Officers as their job title, while $50(22.42 \%)$ were Chief Accountants by job title. Auditors were nine (4.04\%), while top-level job titles such as Finance or Accounts Manager and CFO or Finance Controller were held by $45(20.18 \%)$ and $25(11.21 \%)$ of the respondents, respectively. These results show that the respondents engaged in the study highly involved in the accounting function of their respective firms and could, therefore, provide reliable opinion on their accountings systems and financial reports.

Table 5. Distribution of Firms by Length of Years Accounting System Used

\begin{tabular}{lrrr}
\hline \multicolumn{1}{c}{ Length of Years } & Frequency & Percent & Cum. $\%$ \\
\hline Less than 4 years & 29 & 13.00 & 13.00 \\
4-6 years & 81 & 36.32 & 49.33 \\
7-9 years & 73 & 32.74 & 82.06 \\
10 years \& above & 40 & 17.94 & 100.00 \\
Total & 223 & 100.00 & \\
\hline
\end{tabular}

Note: Extracted by the researcher from research data analysis output

Table 5 presents firms' distribution by the length of time (number of years) their current computerized accounting systems have been in use. From Table 24, only 29 out of 223 firms (13\%) used their computerized accounting systems for less than four years, while the remaining $87 \%$ have used their accounting systems for more than four years. Specifically, 81 firms $(36.32 \%)$ used their systems between four to six years, 73 firms $(32.74 \%)$ between 7 to 9 years, and 40 firms (17.94\%) used their systems for ten or more years. This result indicates that the respondents are conversant with and have adequate knowledge and experience in their respective accounting systems to provide accurate and reliable information about their quality, effectiveness, and financial reporting capabilities.

\subsection{Descriptive Analysis}

The research instrument employed in the study consisted of relevant sections with questions designed in five-point Likert-type scales, which are summated scales to address each study construct. This section presents a descriptive analysis of the research data using Mean (M) and Standard Deviation (SD) to analyze the various constructs that constituted the study variables' dimensions and measures.

\subsubsection{Descriptive Analysis for Computerized Accounting Systems (CAS) Constructs}

The independent (predictor) variable (CAS) consists of five constructs, namely internal controls, automated dataprocessing, relational database, automated reporting, and enhancing technologies. The descriptive analysis results for each of these constructs are presented in Table 6.

From Table 6, the internal controls construct of CAS has an overall minimum response value of 1.20 and maximum value of 5.0, with a mean value of 4.56 and standard deviation of 0.857 . These values are above the threshold marks and, therefore, indicates that the sampled firms had strong internal controls in their accounting systems. The automated data-processing construct has an overall minimum response value of 1.60 and maximum value of 5.0, with a mean value of 4.41 and standard deviation of 0.926 . These values are above the threshold marks and, therefore, indicates that the accounting systems of sampled firms had effective data-processing subsystem. Table 6 also indicates that the relational database construct has an overall minimum response value of 2.60 and maximum value of 5.0, with a mean value of 4.63 and standard deviation of 0.601 . These values are above the threshold marks and, therefore, indicates that the sampled firms had efficient relational database in their accounting systems. The automated reporting construct has an overall minimum response value of 2.0 and maximum value of 5.0, with a mean value of 4.53 and standard deviation of 0.725 . These values are above the threshold marks and, therefore, indicates that the accounting systems of sampled firms had effective automated reporting subsystem. The enhancing technologies construct has an overall minimum response value of 1.80 and maximum value of 5.0, with a mean value of 4.25 and standard deviation of 0.992 . These values are also above the threshold marks and, therefore, indicates that the accounting systems of sampled firms had strong and dependable enhancing technologies. 
Table 6. Descriptive Analysis Results for CAS Constructs

\begin{tabular}{llcccc}
\hline & $\mathrm{N}$ & Min. & Max. & $\mathrm{M}$ & $\mathrm{SD}$ \\
\hline Internal Controls (IC) & 223 & 1.2 & 5 & 4.56 & 0.857 \\
Automated Data-processing (AD) & 223 & 1.6 & 5 & 4.41 & 0.926 \\
Relational Database (RD) & 223 & 2.6 & 5 & 4.63 & 0.601 \\
Automated Reporting (AR) & 223 & 2.0 & 5 & 4.53 & 0.725 \\
Enhancing Technologies (ET) & 223 & 1.8 & 5 & 4.25 & 0.992 \\
Valid N (listwise) & 223 & & & & \\
\hline
\end{tabular}

Note: Extracted by the researcher from research data analysis output.

\subsubsection{Descriptive Analysis for Financial Reporting Quality (FRQ) Constructs}

The dependent (criterion) variable (FRQ) consists of five dimensions, namely relevance, faithful representation, comparability, verifiability, and understandability. The descriptive analysis results for each of these dimensions are presented in Table 7.

From Table 7, the relevance construct of FRQ has an overall minimum response value of 1.0 and maximum value of 5.0, with a mean value of 3.37 and standard deviation of 1.389 . These values are above the threshold marks and, therefore, indicates that there was a sufficient level of relevance in the financial reports of sampled firms. Faithful representation has an overall minimum response value of 1.0 and maximum value of 5.0, with a mean value of 4.01 and standard deviation of 1.292. These values are above the threshold marks and, therefore, indicates that the financial reports of sampled firms had a significant level of faithful representation. Table 7 also indicates that the comparability dimension has an overall minimum response value of 1.0 and maximum value of 5.0 , with a mean value of 3.96 and standard deviation of 1.171. These values are above the threshold marks and, therefore, indicates that the financial reports of sampled firms had a significant level of comparability. The Verifiability dimension has an overall minimum response value of 1.80 and maximum value of 5.0, with a mean value of 4.46 and standard deviation of 0.763 . These values are above the threshold marks and, therefore, indicates that the financial reports of sampled firms had a sufficient level of verifiability. The understandability dimension has an overall minimum response value of 1.40 and maximum value of 5.0, with a mean value of 4.16 and standard deviation of 1.052. These values are above the threshold marks and, therefore, indicates that the financial reports of sampled firms had a sufficient level of understandability.

Table 7. Descriptive Analysis Results for FRQ Dimensions

\begin{tabular}{lccccc}
\hline & $\mathrm{N}$ & Min. & Max. & $\mathrm{M}$ & $\mathrm{SD}$ \\
\hline Relevance (RR) & 223 & 1.0 & 5 & 3.76 & 1.389 \\
Faithful Representation (RF) & 223 & 1.0 & 5 & 4.01 & 1.292 \\
Comparability (RC) & 223 & 1.0 & 5 & 3.96 & 1.171 \\
Verifiability (RV) & 223 & 1.8 & 5 & 4.46 & 0.763 \\
Understandability (RU) & 223 & 1.4 & 5 & 4.16 & 1.052 \\
Valid N (listwise) & 223 & & & &
\end{tabular}

Note: Extracted by the researcher from research data analysis output.

\subsection{Measurement Models Assessments}

In assessing the measurement models for the predictor and criterion variables, the confirmatory factor analysis (CFA) was utilized to substantiate the convergent and discriminant validity of the models using the composite reliability (CR) and average variance extracted (AVE) statistics. The CR and AVE help to ascertain the level of association existing between the various constructs and their respective indicators.

4.3.1 Computerized Accounting Systems (CAS) Measurement Model Assessment

Table 8 shows the summary of the CFA results for computerized accounting systems (CAS) measurement model. All the CAS constructs' loadings were significant at $\mathrm{P}<0.000$. As highlighted by Table 8 , the CR for each of the constructs of CAS ranges between 0.882 and 0.922 , while the AVE ranges between 0.600 and 0.703 . These values were relatively high and indicated strong and satisfactory reliability and convergent validity CAS constructs.

Table 8. Assessment of CAS Measurement Model

\begin{tabular}{lccc}
\hline & CR & AVE & VAVE \\
\hline Internal Controls (IC) & 0.887 & 0.613 & 0.783 \\
Automated data-processing (AD) & 0.922 & 0.703 & 0.839 \\
Relational Database (RD) & 0.913 & 0.681 & 0.825 \\
Automated reporting (AP) & 0.882 & 0.600 & 0.775 \\
Enhancing technologies (ET) & 0.915 & 0.684 & 0.827 \\
\hline
\end{tabular}

Note: Extracted by the researcher from research data analysis output.

4.3.2 Financial Reporting Quality (FRQ) Measurement Model Assessment

Table 9 shows the summary of the CFA results for financial reporting quality (FRQ) measurement model. The loadings of all the FRQ dimensions were significant at $\mathrm{P}<0.000$. From Table 9 , the $\mathrm{CR}$ for each of the constructs 
of FRQ ranges between 0.887 and 0.964 , while the AVE ranges between 0.615 and 0.869 . These values were relatively high and indicated strong and satisfactory reliability and convergent validity for FRQ dimensions.

Table 9. Assessment of FRQ Measurement Model

\begin{tabular}{lccc}
\hline & CR & AVE & $\sqrt{ }$ AVE \\
\hline Relevance (RR) & 0.964 & 0.869 & 0.932 \\
Faithful Representation (RF) & 0.924 & 0.712 & 0.844 \\
Comparability (RC) & 0.944 & 0.648 & 0.805 \\
Verifiability (RV) & 0.917 & 0.736 & 0.858 \\
Understandability (RU) & 0.887 & 0.615 & 0.784 \\
\hline
\end{tabular}

Note: Extracted by the researcher from research data analysis output.

\subsection{Structural Model and Findings}

The study ascertained the validity of the main constructs of the study by estimating the relationship between the high order constructs, computerized accounting systems (CAS), and the formative dimensions of financial reporting quality (FRQ), namely relevance, faithful representation, comparability, verifiability, and understandability. The model, therefore, considered the direct relationship between CAS and relevance (RR), faithful representation (RF), comparability (RC), verifiability (RV), and understandability (RU). The study model had a Chi-Square $(X 2)$ absolute goodness-fit of 79.9 with $\mathrm{P}<0.05$ and 16 degrees of freedom, which indicates a good fit for the model. The $X 2$ absolute fitness was complimented with descriptive fit estimates, such as the Comparative Fitness Index (CFI), Goodness of Fit Index (GFI), and Root Mean Squared Error Approximation (RMSEA), which help to estimate the relative non-centrality for the independence model by comparing the fitness of the specified and independent models (Bagozzi \& Yi, 2012; Hopper et al., 2008). The study model had highly satisfactory values of $0.97,0.89$, and 0.054 for CFI, GFI, and RMSEA, respectively. Therefore, the model was considered fit and theoretically consistent for a reliable interpretation of the parameter estimates and their tests of significance

The structural path estimates are the standardized beta $(\beta)$ values, which represent the refined correlation coefficients after accounting for error terms. The beta $(\beta)$ values range from $0-1$ and may be positive or negative $(-1 \leq \beta \leq 1)$. The beta $(\beta)$ value of \pm 1 represents a perfect relationship, while the value of zero (0) represents no relationship, and the closer the beta $(\beta)$ value is to \pm 1 the stronger the relationship. The variance explanatory power or variance explained (VE) indicates the extent to which the independent variable can predict the dependent variable. The value of VE ranges between zero (0) and one (1) and can be expressed in percentages.

Figure 2 represents the structural path model with parameter estimates, in which the five structural paths, CAS $->$ RR, CAS $->$ RF, CAS $->$ RC, $C A S->$ RV, and CAS $->$ RU, represent the five hypothesized relationships and their respective beta $(\beta)$ values. Figure 2 also shows the predictive power (VE) of computerized accounting systems (CAS) for each of the dimensions of financial reporting (FRQ).

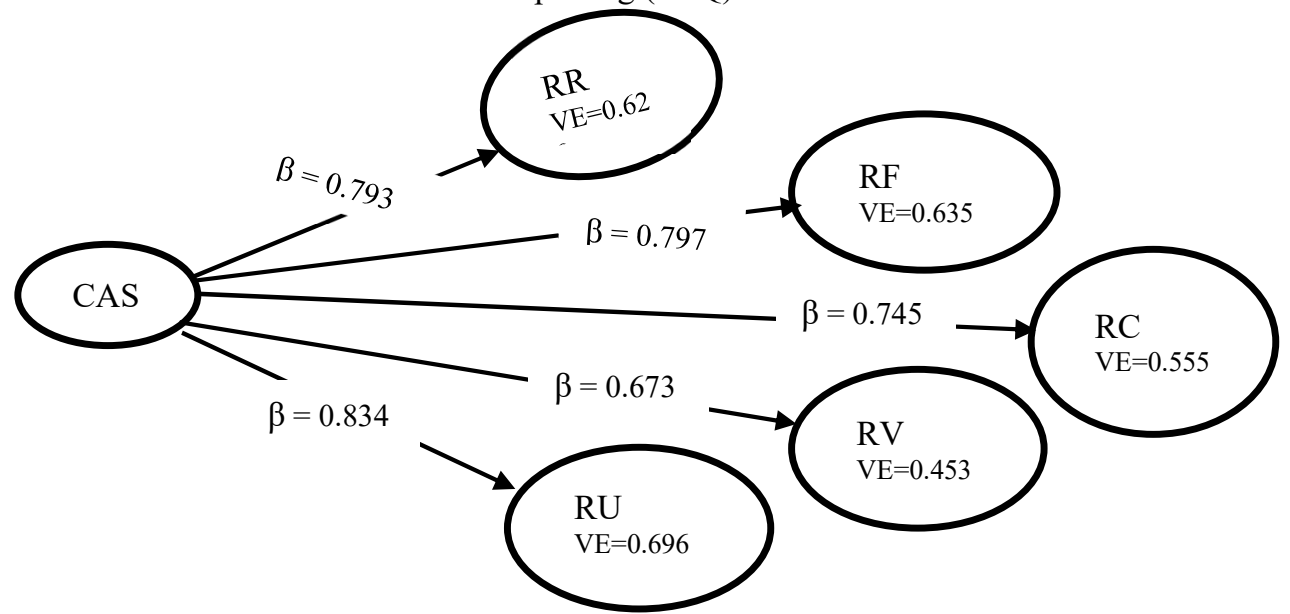

Figure 2. Structural Path Model with Parameter Estimates

Note: Extracted by the researcher from research data analysis out.

4.4.1 Interpretation of the Structural Path Model

The study's structural model results, presented in Figure 2, confirmed a positive and significant relationship between computerized accounting systems (CAS), being the high-order constructs of the study, and financial reporting quality (FRQ). In specific terms, it shows that CAS has a direct positive and significant relationship with all the measures of financial reporting quality, namely relevance, faithful representation, comparability, verifiability, and understandability, with structural path coefficient $(\beta)$ values of $0.793,0.797,0.745,0.673$, and 0.834, respectively, which signify an overall strong positive significant relationship between CAS and FRQ. These 
results, therefore, indicate that computerized accounting systems significantly and positively influence the quality of financial reporting information in terms of relevance, faithful representation, comparability, verifiability, and understandability. Hence, the research question as to what extent do computerized accounting systems influence the quality of financial reporting among SMEs has been favorably answered.

4.4.2 Hypotheses Results

The structural path parameter estimates $(\beta)$ and the variance explanatory power (VE) of the predictor variable (CAS) represent results for the tests of hypotheses employed in the study. All the relationships or structural path results were significant at $\mathrm{P}<0.05$

Parameter $\mathrm{CAS} \rightarrow>$ RR in Figure 2 represented the first hypothesis of the study and established the relationship between computerized accounting systems (CAS) and relevance (RR) dimension of financial reporting quality. This relationship is estimated with a standardized beta $(\beta)$ of 0.793 and variance explanatory power (VE) of 0.629. This implies that computerized accounting systems usage could influence relevance of financial reporting information by $79.3 \%$ and can also predict it with about $63 \%$ certainty. These results, therefore, indicate that CAS has a strong, positive, and significant influence on relevance of financial reporting information. Hence, the null hypothesis that computerized accounting systems do not significantly influence relevance of financial reporting information in SMEs was rejected.

Parameter $\mathrm{CAS}->\mathrm{RF}$ in Figure 2 represented the second hypothesis of the study and established the relationship between computerized accounting systems (CAS) and faithful representation (RF) dimension of financial reporting quality. This relationship is estimated with a standardized beta $(\beta)$ of 0.797 and variance explanatory power (VE) of 0.635 . This implies that computerized accounting systems usage could influence faithful representation of financial reporting information by $79.7 \%$ and can also predict it with about $64 \%$ certainty. These results, therefore, indicate that CAS has a strong, positive, and significant influence on faithful representation of financial reporting information. Hence, the null hypothesis that computerized accounting systems do not significantly influence faithful representation of financial reporting information in SMEs was rejected.

Parameter CAS $->$ RC in Figure 2 represented the third hypothesis of the study and established the relationship between computerized accounting systems (CAS) and comparability (RC) dimension of financial reporting quality. This relationship is estimated with a standardized beta $(\beta)$ of 0.745 and variance explanatory power (VE) of 0.555 . This implies that computerized accounting systems usage could influence comparability of financial reporting information by $74.5 \%$ and can also predict it with about $56 \%$ certainty. These results, therefore, indicate that CAS has a strong, positive, and significant influence on comparability of financial reporting information. Hence, the null hypothesis that computerized accounting systems do not significantly influence comparability of financial reporting information in SMEs was rejected.

Parameter CAS $->$ RV in Figure 2 represented the fourth hypothesis of the study and established the relationship between computerized accounting systems (CAS) and verifiability (RV) dimension of financial reporting quality. This relationship is estimated with a standardized beta $(\beta)$ of 0.673 and variance explanatory power (VE) of 0.453 . This implies that computerized accounting systems usage could influence verifiability of financial reporting information by $67.3 \%$ and can also predict it with about $45 \%$ certainty. These results, therefore, indicate that CAS has a strong, positive, and significant influence on faithful representation of financial reporting information. Hence, the null hypothesis that computerized accounting systems do not significantly influence verifiability of financial reporting information in SMEs was rejected.

Parameter CAS $->$ RU in Figure 2 represented the fifth hypothesis of the study and established the relationship between computerized accounting systems (CAS) and understandability (RU) dimension of financial reporting quality. This relationship is estimated with a standardized beta $(\beta)$ of 0.834 and variance explanatory power (VE) of 0.696 . This implies that computerized accounting systems usage could influence understandability of financial reporting information by $83.4 \%$ and can also predict it with about $70 \%$ certainty. These results, therefore, indicate that CAS has a strong, positive, and significant influence on understandability of financial reporting information. Hence, the null hypothesis that computerized accounting systems do not significantly influence understandability of financial reporting information in SMEs was rejected. The summary of hypotheses results is presented in Table 10. 
Table 10. Summary of Hypotheses Results

\begin{tabular}{|c|c|c|c|c|c|}
\hline \multicolumn{2}{|r|}{ Hypothesis } & \multirow[b]{2}{*}{ P-value } & \multirow[b]{2}{*}{$\begin{array}{c}\text { Beta } \\
(\beta)\end{array}$} & \multirow[b]{2}{*}{$\begin{array}{l}\text { VE } \\
(\beta 2)\end{array}$} & \multirow[b]{2}{*}{ Decision } \\
\hline No. & Description & & & & \\
\hline Ho1 & $\begin{array}{l}\text { CAS do not significantly influence relevance of financial } \\
\text { reporting information. }\end{array}$ & 0.000 & 0.793 & 0.629 & Rejected \\
\hline Ho2 & $\begin{array}{l}\text { CAS do not significantly influence faithful representation } \\
\text { of financial reporting information. }\end{array}$ & 0.000 & 0.797 & 0.635 & Rejected \\
\hline Ho3 & $\begin{array}{l}\text { CAS do not significantly influence comparability of } \\
\text { financial reporting information }\end{array}$ & 0.000 & 0.745 & 0.555 & Rejected \\
\hline Ho4 & $\begin{array}{l}\text { CAS do not significantly influence verifiability of } \\
\text { financial reporting information. }\end{array}$ & 0.000 & 0.673 & 0.453 & Rejected \\
\hline Ho5 & $\begin{array}{l}\text { CAS do not significantly influence understandability of } \\
\text { financial reporting information. }\end{array}$ & 0.000 & 0.834 & 0.696 & Rejected \\
\hline
\end{tabular}

Note: Complied by the researcher from research data analysis output.

\section{Discussions and Conclusion}

\subsection{Discussion of Study Results}

The result of the first hypothesis indicated a strong positive and significant relationship between CAS and the relevance of financial information $(\mathrm{RR})$. The beta value $(\beta)$ of 0.793 indicates a strong positive relationship between the two variables. The p-values of 0.000 indicate a perfect significant relationship at 0.05 significant level. This finding supports the findings of Zare (2012) that accounting information systems (AIS) have a strong effect on the relevance of financial information. This result also supports Attayah and Sweiti (2014) that indicated a positive and significant relationship between ERP (which incorporates AIS) and relevance of financial reporting information. This result collaborates with the result of Mbilla et al. (2020) that also showed a positive and significant relationship between CAS and financial information relevance and that an improvement in CAS would increase the relevance of financial information by $50 \%$. More so, the current result indicates a stronger influence of CAS on the relevance of financial information with a beta value of 0.793 , which implies that an improvement in CAS would lead to a $79.3 \%$ increase in financial information relevance. However, the result of the first hypothesis contradicts the findings of Aryani and Krismiaji (2013) that indicated a negative relationship between ERP and the relevance of financial information. This contradiction could be due to the differences in the models used in measuring financial reporting quality in the different studies. It should be noted that while the current study employed the qualitative characteristics model in measuring relevance, Aryani and Krismiaji (2013) used the accrual model with absolute discretionary values from secondary data. Brazel and Dang (2005) indicated that discretionary accruals tend to encourage earnings management, especially in ERP environments. The results regarding hypothesis one also revealed the model's predictive ability with a VE value of 0.629 , which implies that CAS could be used to predict the relevance (RR) of financial reporting information with $62.9 \%$ certainty. This result is quite instructive to firms and finance and accounting practitioners, who should realize and give attention to the quality of their computerized accounting systems to enhance the relevance of their financial reporting information.

The result of the second hypothesis indicated a strong positive and significant relationship between CAS and faithful representation of financial information (RF). The beta value $(\beta)$ of 0.797 indicates a strong positive relationship between the two variables. The p-values of 0.000 indicate a perfect significant relationship at 0.05 significant level. This finding supports Zare (2012) that showed a significant relationship between AIS and financial information relevance. The findings relating to hypothesis one also support Soudani's (2013) findings that e-accounting (computerized accounting) systems significantly impact financial reporting reliability. The finding also agrees with Sekreye et al. (2017) that CAS quality influences the accuracy (an instance of faithful representation) of financial reporting information. However, this finding contradicts the findings of Pervin et al. (2019) and Aryani and Krismiaji (2013), both of which indicated a negative relationship between ERP (an extension of AIS) and faithful representation of financial information. As noted earlier while discussing the results of the first hypothesis, this contradiction could be a result of the use of qualitative characteristics model in the current study and discretionary accruals in the previous studies by Pervin et al. (2019) and Aryani and Krismiaji (2013), following the fact that discretionary accruals encourage earnings management (Brazel and Dang, 2005). The results regarding hypothesis two also revealed the model's predictive ability with a VE value of 0.635 , which implies that CAS could be used to predict the faithful representation (RF) of financial reporting information with $63.5 \%$ certainty. This result is quite instructive to firms and finance and accounting practitioners, who should realize and give attention to their computerized accounting systems' quality to enhance their financial reporting information's decision usefulness through improved faithful representation.

The result of the third hypothesis indicated a strong positive and significant relationship between CAS and 
comparability of financial information $(\mathrm{RC})$. The beta value $(\beta)$ of 0.745 indicates a strong positive relationship between the two variables. The p-values of 0.000 indicate a perfect significant relationship at 0.05 significant level. There was no previous study identified by the researcher that examines this relationship. Hence, this finding is extremely significant as it sets the precedence regarding the relationship between CAS and comparability of financial information. The results regarding hypothesis three also revealed the model's predictive ability with a VE value of 0.555 , which implies that CAS could be used to predict the comparability (RC) of financial reporting information with $55.5 \%$ certainty. This result is quite instructive to firms and finance and accounting practitioners, who should realize and give attention to their computerized accounting systems' quality to enhance their financial reporting information's comparability.

The result of the fourth hypothesis indicated a strong positive and significant relationship between CAS and verifiability of financial reporting information $(\mathrm{RV})$. The beta value $(\beta)$ of 0.673 indicates a strong positive relationship between the two variables. The p-values of 0.000 indicate a perfect significant relationship at 0.05 significant level. However, this finding disagrees with that of Pervin et al. (2019) that indicated a negative relationship between ERP (an extension of AIS) and verifiability of financial reporting information. The results regarding hypothesis four also revealed the model's predictive ability with a VE value of 0.453 , which implies that CAS could be used to predict the verifiability (RV) of financial reporting information with only $45.3 \%$ certainty. This result is quite instructive to firms and finance and accounting practitioners, who should realize and give attention to the quality of their computerized accounting systems to enhance the decision usefulness of their financial reporting information through improved verifiability. More so, among the five hypothesized direct relationships in the study, the direct relationship between CAS and verifiability of financial information, which is represented by the fourth hypothesis, gave the lowest path coefficient (beta) of 0.673 as well as the lowest variance explanatory power (VE) of 0.453 , implying that CAS influences verifiability of financial reporting information less than it does on other dimensions of financial reporting quality and that it has the worst predictive power on verifiability (with as low as $45.3 \%$ certainty) than it has on the other dimensions of financial reporting quality. The relatively low predictive power of CAS over verifiability of financial information could be associated with the fact that the concept of verifiability as a qualitative characteristic of useful financial information has been recently introduced into the conceptual framework (IASB, 2010, 2018), and therefore, might not have explicitly been taken into consideration by the various accounting software vendors in the development of some of the computerized accounting systems employed by SMEs.

The result of the fifth hypothesis indicated a strong positive and significant relationship between CAS and understandability of financial reporting information (RU). The beta value $(\beta)$ of 0.834 indicates a very strong, positive relationship between the two variables. The p-values of 0.000 indicate a perfect significant relationship at 0.05 significant level. As in the result regarding the third hypothesis, the researcher identified no previous study that examines the relationship between CAS and understandability of financial reporting information. Hence, this finding is quite significant as it sets the precedence regarding the relationship between CAS and the understandability of financial information. The results regarding hypothesis five also revealed the model's predictive ability with a VE value of 0.696 , which implies that CAS could be used to predict the understandability (RU) of financial reporting information with $69.6 \%$ certainty. This result provides exceptional insight to firms and finance and accounting practitioners, who should realize and give attention to the quality of their computerized accounting systems to enhance the understandability of their financial reporting information. This result is also quite instructive that CAS enhances the presentation of financial reporting information that is easily and better understood by users. More so, among the five hypothesized direct relationships in the study, the direct relationship between CAS and understandability of financial information, which is represented by the fifth hypothesis, gave the highest path coefficient (beta) of 0.834 as well as the highest variance explanatory power (VE) of 0.696 , implying that CAS influences understandability of financial reporting information more than it does on other dimensions of financial reporting quality and that it can predict understandability (with about $69.6 \%$ accuracy) much better than it could predict the other dimensions of financial reporting quality.

Overall, the results of the study show a positive and significant relationship between CAS and the various dimensions or measures of financial reporting quality. Therefore, the study's findings support the findings of Kanakriyah (2016) that AIS usage enhances the overall quality of accounting information. The overall findings regarding the first five hypotheses also support the findings of Fitrios et al. (2018), Kuraesin et al. (2019), and Susanto (2017) that AIS exerts a significant influence on accounting information quality. Specifically, Fitrios et al. (2018) indicated that an increase in the quality of AIS would improve accounting information quality by $60.6 \%$, and Kuraesin et al. (2019) revealed 81\% improvement, while Susanto (2017) showed that accounting information quality would improve by $36.9 \%$ ).

\subsection{Conclusion and Recommendations}

\subsubsection{Conclusion}

The result of the study showed a significantly strong and positive relationship between the computerized 
accounting systems and relevance of financial reporting information. Considering the VE value of 0.629, CAS is a good predictor of financial information relevance and could influence it at about $63 \%$ amongst Nigerian SMEs, with the remaining $37 \%$ being accounting for by external or environmental factors not captured in the study model, such firm size, management support, and knowledge and ability of systems users. In other words, about $63 \%$ of financial information relevance depends on the use of computerized accounting systems. This outcome reveals the need for SMEs' management to effectively control such factors to help reduce the unexplained variance below the indicated $37 \%$, which would improve the explained variance and the predictive power of CAS.

The result of the study indicated a significantly high and positive relationship between CAS and faithful representation of financial reporting information. Based on the VE value of 0.635 , it is maintained that CAS is a good predictor of faithful representation and could influence it at about $64 \%$ amongst Nigerian SMEs, with the remaining $36 \%$ being accounting for by external or environmental factors not captured in the study model. In other words, about $64 \%$ of the faithfully represented financial information depends on the use of computerized accounting systems. However, if the exogenous variables such as those earlier mentioned are effectively controlled, the predictive ability of CAS on RF could be increased.

The result of the study also showed a significantly strong and positive relationship between CAS and comparability of financial reporting information. Considering the VE value of 0.555 , the study maintains that CAS is a good predictor of comparability and could influence it at about 55.5\% amongst Nigerian SMEs, with the remaining $44.5 \%$ being accounting for by external or environmental factors not captured in the study model. In other words, about $55.5 \%$ of financial information comparability depends on the use of computerized accounting systems. Hence, the management of SMEs should strategize to effectively control those factors to help reduce the unexplained variance below the indicated $44.5 \%$, which will in turn improve the explained variance and the predictive power of CAS.

The result of the study revealed a significantly high and positive relationship between CAS and verifiability of financial reporting information. With the VE value of 0.453 , CAS has a moderate predicting power of verifiability and could influence it at about $45 \%$ amongst Nigerian SMEs, with the remaining $55 \%$ being accounting for by external or environmental factors not captured in the study model. In other words, about $45 \%$ of the verifiability of financial information depends on the use of computerized accounting systems. Verifiability is, therefore, indicated to be the least impacted dimension of financial reporting quality by computerized accounting systems The relatively low predictive power of CAS over verifiability of financial information could be associated with the fact that the concept of verifiability as a qualitative characteristic of useful financial information has been recently introduced into the conceptual framework (IASB, 2010, 2018), and therefore, might not have been considered explicitly in the development of some of the computerized accounting systems used by SMEs. However, the effective control of the exogenous variables, such as those earlier mentioned, would increase the predictive ability of CAS on verifiability.

The result of the study also indicated a significantly very strong and positive relationship between CAS and understandability of financial reporting information. Considering the VE value of 0.696 , the study maintains that CAS is a good predictor of understandability and could influence it at about $70 \%$ amongst Nigerian SMEs, with the remaining $30 \%$ being accounting for by external or environmental factors not captured in the study model. In other words, about $70 \%$ of financial information understandability depends on the use of computerized accounting systems. Understandability is, therefore, indicated to be the most impacted dimension of financial reporting quality by computerized accounting systems. This outcome informs the need for the management of SMEs to effectively control those factors to help reduce the unexplained variance below the indicated $30 \%$, which will, in turn, improve the explained variance and the predictive power of CAS

On the whole, the study provides empirical evidence that computerized accounting systems have significant positive influence on the quality of financial reporting among small and medium enterprises in Nigeria, and that based on the obtained beta $(\beta)$ values, an improvement in the quality and effectiveness of computerized accounting systems could enhance the quality of financial reporting information in terms of relevance, faithful representation, comparability, verifiability, and understandability by $79.3 \%, 79.7 \%, 74.5 \%, 6703 \%$, and $83.4 \%$, respectively. The study's findings also showed that the most impacted dimension of financial reporting quality by CAS is understandability, while the least impacted is verifiability The study is, therefore, significant as it adds to the body of theoretical and practical knowledge in accounting information systems and financial reporting by providing empirical evidence on the relationship between computerized accounting systems and the quality of financial reporting information among Nigerian SMEs.

5.2.2 Recommendation

Based on the outcome of the studies, the following recommendations have been provided.

The management of SMEs should ensure that the quality of the computerized accounting systems to be deployed is rigorously evaluated before implementation as the quality of the accounting system has been found to predict or influence the quality of financial reporting information. This goal could be achieved by employing accounting staff with a reasonable knowledge of the adopted accounting system or engaging outside consultants who 
specialize computerized accounting systems implementation and administration.

The management of SMEs should endeavor to identify and understand exogenous factors that might negatively impact their computerized accounting systems' predictive power. This practice would help maintain or even improve the predictive ability of CAS, which would enhance their financial reporting quality. Those external factors that are not captured in the study model which exert influence on the performance and predictive ability of computerized accounting systems, such as the ability of system users, the number of employees, educational background of management and accounting personnel, management support, systems maintenance routine, and organizational structure, should be adequately simulated for a fuller understanding of the enormity of their potential impact, and proactive steps should be taken to ensure that such impact is drastically minimized.

Proper training should be given to accounting personnel in SMEs on the use of computerized accounting systems. This effort would help improve their skills and understanding of the accounting systems adopted by their firms. Gaining a better understanding of the accounting system would result in their effective, efficient, and optimal usage of the systems, which will guarantee the system's efficiency and, consequently, the production of good quality financial reporting information.

The management of SMEs should assign the administration of their computerized accounting systems to dedicated personnel who are not involved in the routine accounting function to ensure that the systems are effectively managed and that internal controls features are effectively implemented. This practice would also ensure that the systems are effectively managed and regularly maintained for optimal performance. When the systems are performing efficiently, the production of high-quality financial information will be guaranteed.

Since verifiability as a measure of the quality of financial reporting information is a recent concept, computerized accounting systems developers and vendors should endeavor to enhance their systems' business logic towards improving financial information verifiability. This necessary because the available systems employed by SMEs are indicated in this study to have a low predictive power over the verifiability of financial information.

One of the major objectives of international financial reporting standards (IFRS) adoption by the Nigerian government was to improve the quality of financial reporting amongst firms. Since computerized accounting systems have been indicated to predict financial reporting quality, efforts should be made by relevant government agencies, such as the Small and Medium Enterprises Development Agency (SMEDAN), to educate SMEs on the need to implement good quality and standardized computerized accounting systems. They should also initiate policy guidelines on computerized accounting systems implementation for SMEs, as well as ensure strict compliance to such policies. This effort would go a long way to ensuring the effective implementation of computerized accounting systems by SMEs, and consequently enhancing their financial reporting quality.

The researcher also recommends that government agencies responsible for the regulation and assessment of academic quality in tertiary educational institutions in Nigeria, such as the National Universities Commission (NUC), the National Board for Technical Education (NABTEC), and the National Council for Colleges of Education (NCCE), should make efforts to update or reform the Accounting Curriculum of their respective categories of institutions to include Computerized Accounting and IFRS courses. This development would help produce graduates of Accounting that are reasonably knowledgeable in computerized accounting systems and IFRS, who would consequently help to effectively deliver on these aspects of the accounting function in their future engagements. When the accounting systems are employed by knowledgeable personnel, their optimal performance, and predictive power on financial reporting quality would be guaranteed.

To help validate and, or, extend the findings of this study, further studies could be carried out using a different sampling frame or engaging larger firms as the study population.

\section{References}

Abdallah, A. A. J. (2013). The impact of using accounting information systems on the quality of financial statements submitted to the Income and Sales Tax department in Jordan. European Scientific Journal, 1, 4148.

Afolabi, M. O. (2013). Effect of financial reporting on investment decision making of manufacturing firms in Nigeria. European Journal of Humanities and Social Sciences, 22(1), 1127-1142.

Agrawal, A., \& Chadha, S. (2005). Corporate governance and accounting scandals. The Journal of Law and Economics, 48(2), 371-406. https://doi.org/10.2139/ssrn.595138

Agung, M. (2015). Accounting information systems and improvement on financial reporting. International Journal of Recent Advances in Multidisciplinary Research, 2(11), 950-957.

Al-Dalabih, F. A. N. (2018). The impact of the use of accounting information systems on the quality of financial data. International Business research, 11(5), 143-158.

Al-Dmour, A., Abbod, M. F., \& Al-Dmour, H. H. (2017). Qualitative characteristics of financial reporting and non-financial business performance. International Journal of Corporate Finance and Accounting, 4(2), 1-22.

Al-Dweikat, M. F. S. \& Nour, M. I. (2018). A structural equation model for analyzing the impact of strategic management accounting techniques on quality of financial information. International Journal of Economics 
and Finance, 10(4), 62-71.

Alsaaty, F. M. (2012). The cycle of births and dirths of U.S. employer firms. Journal of Management and Marketing Research, 11, 1-12.

Amanamah, R. B., Morrison, A., \& Asiedu, K. (2016). Computerized accounting systems usage by small and medium scale enterprises in Kumasi Metropolis, Ghana. Research Journal of Finance and Accounting, 7(16), $16-29$.

Amidu, M., Effah, J. \& Abor, J. (2011). E-Accounting practices among small and medium enterprises in Ghana. Journal of Management Policy \& Practice, 12(4), 146-155.

Anggraeni, A. F. (2016). Correlation between information technology and management information systems quality. International Journal of Scientific \& Technology Research, 5(6), 168-172.

Aremu, M. A., \& Adeyemi, S. L. (2011). Small and medium scale enterprises as survival strategy for employment generation in Nigeria. Journal of Sustainable Development, 4(1), 200-206.

Aryani, Y. A., \& Krismiaji. (2013). Enterprise resource planning implementation and accounting information quality. GSTF Journal on Business Review, 2(4), 25-31.

Attayah, O. F., \& Sweiti, I. M. (2014). Impact of ERP system using on the accounting information relevance: Evidence from Saudi Arabia. GSTF Journal on Business Review (GBR), 3(2), 1-6.

Bagozzi, R. P., \& Yi, Y. (2012). Specification, evaluation, and interpretation of structural equation models. Journal of the Academy of Marketing Science, 40, 8-34. doi.org/10.1007/s11747-011-0278-x

Boateng, A., \& Abdulrahman, M. D. (2013). Micro small-sized enterprises and bank credit: Evidence from West Africa. Journal of Emerging Market Finance, 12(2), 129-150.

Brazel, J. F., \& Dang, L. (2005). The effect of ERP systems implementation on the usefulness of accounting information. Management Audit Journal, 20(6), 619-631.

Brownell, P., \& Hirst, M. K. (1986). Reliance on accounting information, budgetary participation and task uncertainty: Tests of a three-way interaction. Journal of Accounting Research, 24(2), 241-249.

Chen, T. (2012). Analysis on accrual-based models in detecting earnings management. Lingnan Journal of Banking, Finance and Economics, 2(5), 1-11.

Choe, JM. (1998). The effect of user participation on the design of accounting information systems. Information \& Management, 34(3), 185-198. https://doi.org/10.1016/S0378-7206(98)00055-X

Collis, J. \& Hussey, R. (2014) Business research: A practical guide for undergraduate and postgraduate students. 4th ed. Palgrave-MacMillan.

Committee of Sponsoring Organizations of the Treadway Commission. (2013). Internal control-integrated framework: Executive summary. http://www.coso.org/documents/990025P Executive Summary final may20 e.pdf

Doll, W.J., \& Torkzadeh, G. (1998a). Developing a multidimensional measure of systems use in an organizational context. Information \& Management, 33(4), 171-185.

Doll, W. J., \& Torkzadeh, G. (1988b). The measurement of end-user computing satisfaction. MIS Quarterly, 12, 259-272. dx.doi.org/10.2307/248851

Ernst \& Young. (2010). Conceptual framework: Objectives and qualitative characteristics. Supplement to IFRS Outlook, 86, 1-3. Retrieved from https://www.ey.com/IFRS/

Fardinal. (2013). The quality of accounting information and the accounting information system through the internal control systems: A study on Ministry of State Agencies of the Republic of Indonesia. Research Journal of Finance and Accounting, 10(10), 1-14.

Fitrios, R., Susanto, A., Soemantri, R., \& Suharman, H. (2018). The influence of environmental uncertainty on the accounting information system quality and its impact on the accounting information quality. Journal of Theoretical and Applied Information Technology, 96(21), 7164-7175.

Frimpong, K. A., Yawson, I. K., \& Akomeah, E. A. (2018). Computerized accounting in Ghana: The shift from books to software: The benefits and challenges associated with the transition. International Journal of Advanced Research and Development, 3(6), 46-53.

Ghasemi, M., Shafeiepour, V., Aslani, M., \& Barvayeh, E. (2011). The impact of information technology (IT) on modern accounting systems. Procedia - Social and Behavioural Sciences, 28, 112-116.

Gorton, M. (1999). Use of financial management techniques in UK-based small and medium sized enterprises: Empirical research findings. Journal of Financial Management and Analysis, 12(1), 56-64.

Grande, E. U., Estabanez, R. P., \& Colomina, C. M. (2011). The impact of accounting information systems (AIS) on performance measures: Empirical evidence from Spanish SMEs. The International Journal of Digital Accounting Research, 11, 25-43.

Greuning, H., Scott, D., \& Terblanche, S. (2011). International financial reporting standards: A practical guide. (6th ed.). The International Bank for Reconstruction and Development/The World Bank.

Hurt, R. L. (2013). Accounting information systems: Basic concepts and current issues (3rd ed). McGrawHill/Irwin. 
Ige, M. S. (2015). The impact of computerized accounting information system on the performance of the banking industry in Nigeria (Master's thesis, University of Lagos, Nigeria).

http://papers.ssrn.com/sol3/papers.cfm?abstract_id=2664327

International Accounting Standards Board [IASB]. (2010). The conceptual framework for financial reporting. IFRS Foundation. Retrieved 12 October 2018 from http://eifrs.ifrs.org/eifrs/UnaccompaniedConceptual

International Accounting Standards Board [IASB]. (2015). International Financial Reporting Standard for Small and Medium-sized Entities (IFRS for SMEs) http://eifrs.ifrs.org/eifrs/sme/en/IFRS\%20for\%20SMEs_Standard_2015.pdf

International Accounting Standards Board [IASB]. (2018). Conceptual framework for financial reporting. Project summary. IFRS Foundation. https://www.ifrs.org/-/media/project/conceptual-framework/fact-sheetproject-summary-and-feedback-statement/conceptual-framework-project-summary.pdf

Islam, S., \& Abedin, Z. (2013). Impact of data mining on relational database management system centric business environments. International Journal of Computer Applications, 75(3), 21-27.

Ismail, N. A., \& King, M. (2007). Factors influencing the alignment of accounting information in small and medium sized Malaysian firms. Journal of Information Systems and Small Business, 1(1/2), 1-20.

Itang, A. E. (2018). Challenges impeding effective implementation of internal accounting controls in computerized systems: A survey of Nigerian SMEs. Proceedings of the 2018 International Doctoral Conference of LIGS University, Honolulu, USA, August 30, 2018, 69-76. https://www.ligsuniversity.com/data/2018-12-20-11-06-56-International-Doctoral-Conference-of-LIGSUniversity-New-Challenges-in-Global-Economy.pdf

Itang, A. E. (2020a). Computerized accounting systems: Measuring structural characteristics. Research Journal of Finance and Accounting, 11(16), 38-54. doi.org/10.7176/RJFA/11-16-05

Itang, A. E. (2020b). Do small and medium enterprises optimally utilize computerized accounting systems internal controls? An empirical study. Research Journal of Finance and Accounting, 11(20), 16-28. doi.org/10.7176/RJFA/11-17-03

Itang, A. E. (2021). The contributory impact of structural components of computerized accounting systems on the systems' overall performance. Research Journal of Finance and Accounting, 12(18), 101-110. doi.org/10.7176/RJFA/12-18-11

Kanakriyah, R. (2016). The effect of using accounting information systems on the quality of accounting information according to users' perspective in Jordan. European Journal of Accounting, Auditing and Finance, 4(11), 58-75.

Kapasi, B. (2017). Redefinition of accounting in computerized accounting environment - A Study. International Research Journal of Management Science and Technology, 8(2), 1-6.

Kpolovie, P. J. (2016). Excellent research methods. Partridge Publishing.

Krejcie, R. V. \& Morgan, D. W. (1970). Determining sample size for research activities. Educational and Psychological Measurement, 30(3), pp. 607-610.

Kuraesin, A. D., Sueb, M., \& Fitrijanti, T. (2019). The effect of management support on the quality of accounting information systems and its impact on the quality of accounting information (in private higher education in Bandung city). International Journal of Mechanical Engineering and Technology (IJMET), 10(3), 450-456.

Lalin, H., \& Sabir, R. I. (2010). Research on usage and usefulness perception of financial accounting practices in less developed countries: A case of Cambodia. Proceedings of the 7th International Conference on Innovation and Management, 1881-1885.

Maines, L., \& Wahlen, J. (2006). The nature of accounting information reliability: Inferences from archival and experimental research. Accounting Horizons, 20(4), 399-425.

Marivic, A. (2009). Evaluating the security of computerized accounting information systems: An empirical study on Egyptian banking industry (Unpublished doctoral thesis). Aberdeen University, UK.

Masanja, N. M. (2019). The impact of computer accounting system on the financial performance for selected private companies in Arusha, Tanzania. International Journal of Innovation in Education and Business, 1(1). $1-7$.

Mbilla, S. A. E., Nyeadi, J. D., Akolgo, D. A., \& Abiire, M. A. (2020). Impact of computerized accounting systems on the quality of financial reports in the Banking Sector of Ghana. European Journal of Business and Management, 12(17), 114-121.

Mbobo, M. E., \& Ekpo, N. B. (2016). Operationalizing the qualitative characteristics of financial reporting. International Journal of Finance and Accounting, 5(4), 184-192.

McDaniel, L., Martin, R. D., \& Maines, L. A. (2002). Evaluating financial reporting quality: The effects of financial expertise vs. financial literacy. The Accounting Review, 77, 139-167.

Meiryani, M., Susanto, A., \& Sudrajat, J. (2019). The effect of environmental complexity on the quality of accounting information systems: Integration flexibility and complexity dimensions. ICETT 2019: Proceedings of the 2019 5th International Conference on Education and Training Technologies, May 2019, 
$115-119$.

Mele, C., Pels, J., \& Polese, F. (2010). A brief review of systems theories and their management applications. Service Science, 2(1/2), 126-135.

Mujat, D-E., Cristescu, M. P., Ciovica, V. L. \& Ciovica, I. L. (2013). The using of open-source products in developing the accounting of SMEs. Revista Academiei Fortelor Terestre, 18(4), 411-415.

Mundy, J. \& Owen, C. A. (2013). The use of ERP system to facilitate regulatory compliance. Information Systems Management, 30(3), 182-197.

Nichols, D., \& Wahlen, J. (2004). How do earnings numbers relate to stock returns? A review of classic accounting research with updated evidence. Accounting Horizons, 18(4), 263-286.

Nigerian Accounting Standards Board. (2010). Report of the committee on road map to the adoption of international financial reporting standards in Nigeria. Nigeria Accounting Standards Board. https://www.proshareng.com/admin/upload/report/IFRSROADMAPCOMMITTEEINALREPORT.pdf

Obamuyi, T. M. (2007). An exploratory study of loan delinquency among small and medium enterprises (SMEs) in Ondo State of Nigeria. Labour and Management Development Journal, 8, 1-10.

Ohachosim, C. I., Onwuchekwa, F. C., \& Ifeanyi, T. T. (2012). Financial challenges of small and medium-sized enterprises (SMEs) in Nigeria: The relevance of accounting information. Review of Public Administration $\&$ Management, 1(2), 248-276.

Okoli, B. E. (2011). Evaluation of the accounting systems used by small scale enterprises in Nigeria: The case of Enugu - South East Nigeria. Asian Journal of Business Management, 3(4), 235-240.

Onugu, B. A. N. (2005). Small and medium enterprises in Nigeria: Problems and prospects (Doctoral dissertation, St. Clement University). Retrieved from http://stclements.edu/grad/gradonug.pdf

Paganini, C. (2019). Primer: Understanding software and system architecture. Online: The New Stack. Retrieved 13 April 2020 from https://thenewstack.io/primer-understanding-software-and-system-architecture/

Pervin, M. T., Sarkar, J. B., \& Bala, S. K. (2019). Effect of ERP implementation on faithful representation and verifiability of accounting information leading to earnings management: Bangladesh Perspective. DUET Journal, 5(1), 67-75.

Qatanani, K. M. \& Hezabr, A. A. (2015). The effect of using accounting information systems to improve the value chain in business organisations - Empirical study. European Journal of Accounting Auditing and Finance Research, 3(6), 1-11.

Rae, S., Salhin, A., Taheri, B., Porter, C., Konig, C., \& Valantasis-Kanellos, N. (2016). Approaches to quantitative data analysis and evaluation. In A. Paterson, D. Leung, W. Jackson, R. Maclntosh, \& K. O'Gorman (Eds.). Research methods for accounting and finance (pp. 187-210). Goodfellow Publishers Limited.

Ramakrishnan, R., \& Gehrke, J. (2003). Database management systems (3rd ed). McGraw-Hill.

Ramdany. (2015). Influence of the quality of accounting information systems and the effectiveness of internal controls on financial reporting quality. Research Journal of Finance and Accounting, 6(6), 143-152.

Rani, D. L., \& Kidane, F. (2012). Characteristics and important quality factors of management accounting information system. Radix International Journal of Banking, Finance and Accounting, 1(7), 1-18.

Richard, G., McMahon, P., \& Holmes, S. (1991). Small business financial management practices in North America: A literature review. Journal of Small Business, (April), 19-29.

Sacer, I. M., \& Oluic, A. (2013). Information technology and accounting information systems' quality in Croatian middle and large companies. Journal of Information and Organizational Sciences, 37(2), 117-126.

Saracina, T. H. (2011). An examination of the use of accounting information systems and the success of small businesses in South Carolina (UMI Number: 3507836) [Doctoral dissertation, Nova Southeastern University]. ProQuest Dissertations \& Theses Global.

Satalkar, B. (2018). 10 Great advantages of database management systems you never realized. Techspirited.Com. Retrieved 2 January 2020 from www.https://techspirited.com/advantages-of-database-management-systems

Sekyere, A. M., Amoateng, A. K., \& Frimpong, K. (2017). The determinants of Computerized accounting system on accurate financial report in listed banks on the Ghana stock exchange. International Journal of Finance and Accounting, 6(4), 104-110.

Seyed, M. M. (2014). The relationship between financial reporting quality and investment efficiency in Tehran stock exchange. International Journal of Academic Research in Business and Social Sciences, 4(6), 104-113. http://dx.doi.org/10.6007/IJARBSS/v4-i6/930

Shiraj, M. M. (2015). The impact of using computerized accounting systems (CAS) in financial reporting among SMEs: (Special reference to the South Eastern Region, Sri Lanka). Proceedings of the 5th International Symposium, South Eastern University of Sri Lanka, 2015.

Small and Medium Enterprises Development Agency of Nigeria [SMEDAN]. (2010). Survey report on micro, small and medium enterprises (MSMEs) in Nigeria, 2010. SMEDAN.

http://www.smedan,gov.ng/images/collaborative\%20survey\%20report.smedan-nbs.pdf

Small and Medium Enterprises Development Agency of Nigeria [SMEDAN]. (2013). SMEDAN and National 
Bureau of Statistics collaborative survey: Selected findings (2013). SMEDAN. https://smedan.gov.ng/images/PDF/2013-MSME-Survey-Summary-Report.pdf

Soudani, S. N. (2013). The impact of implementation of e-accounting system on financial performance with effects of internal control systems. Research Journal of Finance and Accounting, 4(11), 1-11.

Steckel, A. J. (2011). Analysis of QuickBooks internal control utilization (Honours programme thesis, University of Northern Iowa). UNI Scholars Works. http://scholarworks.uni.edu/cgi/viewcontent.cgi?article=1005\&context=hpt

Susanto, A. (2017). How the quality of accounting information system impact on accounting information quality (Research on higher education in Bandung). Journal of Engineering and Applied Sciences, 12(14), 36723677.

Tanwongsval, V., \& Pinvanichkul, T. (2008). Accounting information requirements and reporting practices of Thai SMEs. JAP King Mongkut University Technology, 8, 59-74.

United States Small Business Administration [USSBA]. (2018). United States small business profile, 2018. SBA Office of Advocacy. www.sba.gov/sites/default/files/advocacy/2018-Small-Business-Profile-US.pdf

van Beest, F., Braam, G., \& Boelens, S. (2009). Quality of financial reporting: Measuring qualitative characteristics. NiCE Working Paper No. 09-108, Radbound University, Nijmegan, Netherlands. https://www.ru.nl/publish/pages/516298/nice 09108.pdf

von Bertalanffy, L. (1950). An outline of general systems theory. The British Journal of the Philosophy of Science, $1(2), 134-165$.

von Bertalanffy, L. (1968). General systems theory: Foundations, development, applications. George Braziller Inc.

von Bertalanffy, L. (1972). The history and status of general systems theory. The Academy of Management Journal, 15(4), 407-426.

Zare, I. (2012). Study of effect of accounting information systems and software on qualitative features of accounting information. International Journal of Management Sciences and Business Research, 1(4), 1-12. 